\title{
Improving the Efficiency of Using Hydraulic Reverse Shovel Excavators on Inclined and Steeply Dipping Fields by Controlling the Overburden Rate
}

\author{
Tatiana Tyuleneva ${ }^{1,2, *}$, Egor Loginov ${ }^{3}$, Marat Moldazhanov ${ }^{4}$, and Evgeny Plotnikov ${ }^{5}$ \\ ${ }^{1}$ T.F. Gorbachev Kuzbass State Technical University, Department of Management Accounting and \\ Analysis, 650000 Kemerovo, 28 Vesennya st., Russian Federation \\ ${ }^{2}$ Branch of T.F. Gorbachev Kuzbass State Technical University in Prokopyevsk, Department of \\ Social and Humanitarian Disciplines, 653049 Prokopyevsk, 19a Nogradskaya st., Kemerovo region - \\ Kuzbass, Russian Federation \\ ${ }^{3}$ Saint-Petersburg Mining University, Department of Mineral Deposits Development, 199106 Saint- \\ Petersburg, 2 Line 21 V.I., Russian Federation \\ ${ }^{4}$ Kazakh Humanitarian-Law Innovative University, Department of Finance and Accounting, 11 \\ Mangilik el st., Semey, East Kazakhstan region, 071400, Republic of Kazakhstan \\ ${ }^{5}$ T.F. Gorbachev Kuzbass State Technical University, Mezhdurechensk Branch, 652881 \\ Mezhdurechensk, 36 Stroiteley st., Russian Federation
}

\begin{abstract}
The economic efficiency of open-pit mining is largely determined by the choice of a rational mining regime, which is associated with the problem of averaging the operational overburden rate over periods. At the same time, the authors do not always give recommendations when averaging the operational rates of overburden and the implementation of the selected mode of open-pit mining in practice, most often associated with determining the changing width of the working site throughout its entire existence. The article describes a method for controlling the operational overburden rate when using hydraulic reverse shovel excavators using elements of mathematical modeling of averaging the operational overburden rate, which provides high accuracy of the results and eliminates the influence of the human factor on their calculation.
\end{abstract}

\section{Introduction}

Currently, open-pit mining is developing in a certain direction, associated with the use of more advanced equipment with significant linear dimensions, which in turn leads to an increase in the parameters of the development system. One of the main technological processes in the development of mineral deposits of mineral resources in the open way is excavation and loading operations. The global trend shows that for mining enterprises, the

\footnotetext{
* Corresponding author: $\underline{\text { rrukta@mail.ru }}$
} 
share of using rope shovels is decreasing in favor of more actively developing hydraulic reverse shovels [1-3].

In the case of open-pit mining of mineral deposits, the volumes of overburden removed from the quarry, as a rule, are several times higher than the volume of valuable minerals. Since the enclosing rocks, which make up the main part of overburden rocks, are close to the mineral in terms of physical and mechanical properties, labor costs for excavation. Therefore, total cost of mining is formed, to a large extent, with the cost of overburden removal. Determining the productivity of a quarry by overburden is a very relevant area of research for improving efficiency, and the overburden rate itself is one of the main indicators of the effective operation of a modern section.

\section{Theory of Experimental Research}

Mining and geometric analysis of the quarry field remains one of the main methods for calendar planning and determining the rational mode of mining operations. However, this method has some disadvantages - high labor intensity, the need for maximum accuracy of the initial data, the uncertainty of the initial position of mining operations, the need to build a new curve $V=f(P)$ at $\varphi_{\max }$ and $B=B_{\min }$ when changing the direction of the excavation. In addition, in the case when the curves for $\varphi=\max$ and $\varphi=0^{\circ}$ are located too close to each other, there is uncertainty of the final results. This method is widely used in practice, but its implementation shows the above disadvantages, which can be avoided when describing this method in mathematical form [4-5].

The averaging of the operational overburden rate is achieved by varying the angle of inclination of the working side of the quarry over time due to the corresponding change in the width of the working platforms. In average the operational overburden rate using existing methods, specific recommendations have not yet been developed for the implementation of the selected mining mode in the practical planning of mining operations at the quarry, most often associated with determining the changing width of the working area (WWA) throughout the entire life of the field in the open pit. To implement the method, it is necessary to know the development system, the opening scheme and the direction of the deepening in the quarry space, to have cross-sections or segmental plans with the boundaries of the quarry applied at the end of mining [6].

One of the conditions for the normal operation of a modern quarry is to maintain a sufficient width of working areas during the entire period of its operation. The design dimensions of the working areas are calculated values averaged over the length of the work front and to a certain extent depend on the intensity of the movement of the working ledges and the accepted provision of the quarry with ready-to-excavate reserves of rock mass. In real practice, the width of the working areas along the length of the front varies around the average values due to the discreteness of the technological processes.

There are two extreme values for the width of the work area. The minimum width of the work area serves as a criterion limiting the reduction of work areas. It is set by the project individually, is a calculation criterion and is regulated by regulatory documents. The maximum width of the working area, at which the development of the field is carried out almost in layers, is determined by the size of the quarry field in the plan, but mining operations in the deep development systems with maximum working areas are almost impossible, and there is also a problem of preparing the underlying horizon for excavation.

Different methods of determining the width of the work area were studied. It is worth noting that to determine this parameter, there are a large number of different methods and techniques: the method of calculation in rocks using the drilling and blasting method of preparing the rock mass for excavation (the main indicator is the width of the collapse of the ledge after the explosion); the method of calculation for loose, soft rocks extracted 
without preliminary loosening (the main indicator is the width of the entrance). In turn, these methods can be divided into subsections: the geometric method (the main indicator is the slope angle of the working side of the quarry $\varphi$ ); the method that takes into account the parameters of the excavation and loading equipment (the main indicators are the parameters of a single-bucket excavator); the method that takes into account the parameters of transport equipment (the main indicators are the parameters of vehicles) [7-8].

Different types of buckets used on hydraulic reverse shovel excavators were considered. An increase in the size of mining equipment leads to an increase in the probability of accidents at work. To reduce this trend, it is necessary that the work is carried out according to the mining project. The minimum width of the working areas is determined in accordance with the arrangement of the removal and loading equipment and the scheme of the entrance of dump trucks for loading. The width of the working area should provide the possibility of productive work of the excavation and transport equipment. For specific production situations, the necessary set of elements is specified that determine the values of the width of the working area of the existing quarry. The minimum width dimensions of the working area are determined depending on the technical parameters of the equipment of the technological complex used (excavator - dump truck). When determining the minimum width of the working area using hydraulic reverse shovel excavators, it is necessary to take into account the advantages of this equipment.

The experience of mining enterprises and design organizations shows that for a given performance of a quarry for mineral resources, the main tool for managing the mining regime is the variation of the overburden rate. In most cases, the graphic expression of the overburden mode is a polyline. When developing steeply falling fields or fields with mountainous terrain, the overburden schedule at the beginning of the field development has an ascending period, when the maximum point is reached, an inflection point appears, and at the end of the development, the schedule has a descending period.

When choosing the mining regime, the most commonly used adjustable parameters of the development system are: the length of the mining front, the width of the working areas, the height of the ledge. It is not always possible to simultaneously increase the productivity of a quarry for minerals and reduce the volume of overburden. Most often, an increase in the productivity of a quarry for a mineral leads to an increase in the volume of overburden, and a decrease in the overburden rate can lead to a decrease in the productivity of a quarry for a mineral, which is often an average value. In this regard, studies aimed at stabilizing the mining regime by controlling the operational overburden rate are relevant.

\section{Results and Discussion}

One of the most effective ways to regulate the regime of mining operations is to change the angle of the slope of the working side. Changing the width of the working areas gives to vary the angle of the working side, which, in turn, gives to approach the method of controlling the operational rate of overburden. Changing the slope angle of the working side of the quarry $(\varphi)$ is possible within the two extreme values of $\varphi$ max and $\varphi \rightarrow 0$ (Figure 1) for inclined and steeply falling deposits.

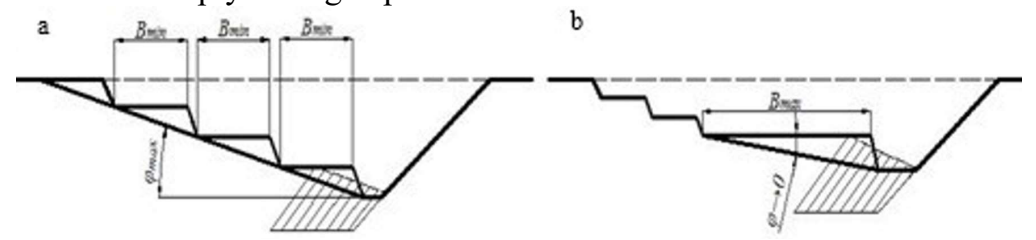

Fig. 1. Extreme possible cases of working out a quarry [7]. 
In order to achieve a uniform mining regime with a set mineral productivity, the main way to average the volume of overburden operations is to redistribute their peak values over time. This method can be implemented in two main ways: transfer of peak volumes to an earlier period (Figure 2 a) and transfer of peak volumes to a later period of operation of the quarry (Figure $2 \mathrm{~b}$ ).
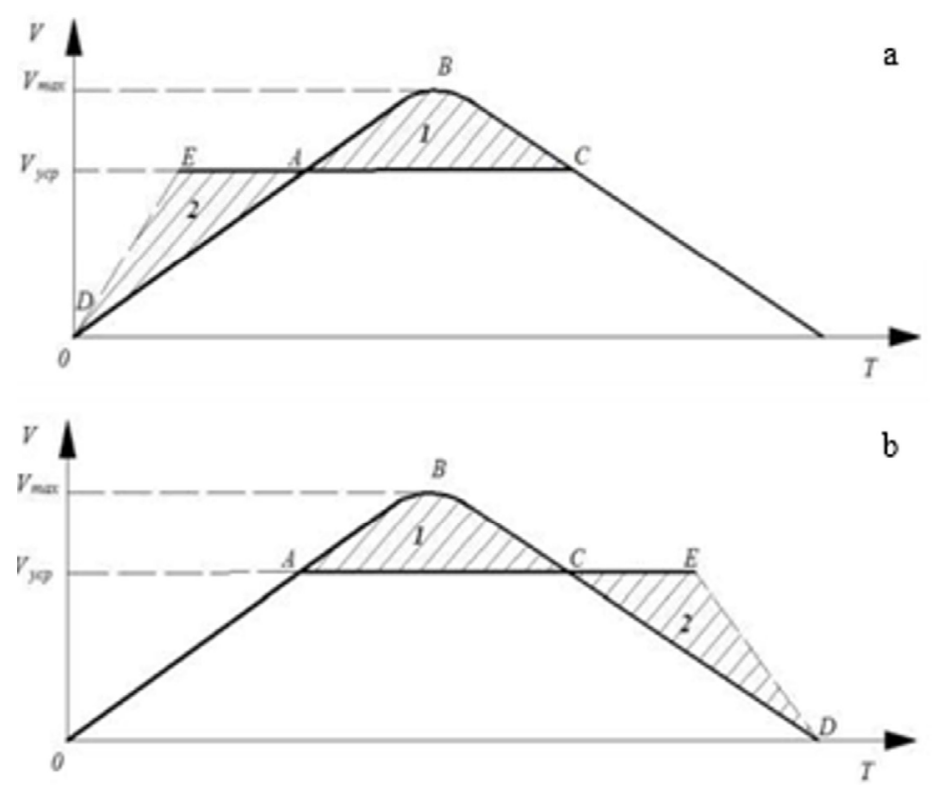

Fig. 2. Transfer of peak overburden volumes: $a-$ to an earlier period, $b$ - to a later period of field development [7].

In nature, there are no two identical deposits, moreover, even in the study of one quarry, depending on the order of development of the work front and the selected parameters of the development system, the forms of the graphs will be different. Based on this, it is impossible to create a standard approach to describing the behavior of the operational overburden rate, but it is possible to identify a number of dependencies that improve the study of this indicator.

The dependence of the slope angle of the working side on the width of the working area is deterministic and can be represented by the graph $\varphi=f(W W A)$ at reference values (Figure 3). 


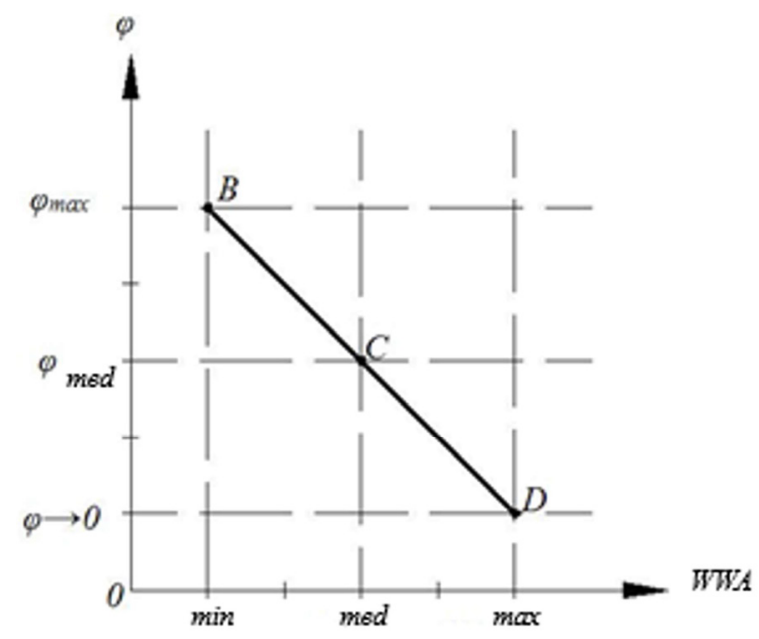

Fig. 3. Dependence of the slope angle of the working side on the width of the working area [8].

Figure 3 shows that the segment $B D$ determines the dependence of the slope angle of the working side of the quarry on the width of the working area under normal conditions. Normal conditions are considered to be the operation of a quarry within the two extreme values of the width of the working area. Point $B$ is used to limit the minimum width of the working area at the maximum angle of the slope. Point $C$ is the average value of the width of the working area and the angle of the slope of the working side. The point $D$ represents the limit of the maximum width of the working area at the minimum angle of the slope of the working side.

Based on the analysis of the dependence of the slope angle of the working side on the width of the working area, it is possible to proceed to the study of the dependence of the operational overburden rate on the angle of the working side (Figure 4 a) and the width of the working area (Figure $4 \mathrm{~b}$ ). Based on the study of this parameter, it is possible to draw up a graph of the dependence of the operational overburden rate on the angle of the slope of the working side of the quarry $k=f(\varphi)$; and the next one is of the operational overburden rate on the width of the working area $k=f(W W A)$. The segment $B D$ (Figure $4 \mathrm{a}, \mathrm{b}$ ) determines the dependence of the operational overburden rate on the slope angle of the working side of the quarry or the width of the working area under normal conditions. Normal conditions are considered to be the operation of a quarry within the two extreme values of the slope angle of the working side or the width of the working area. Point $B$ is used to limit the minimum angle of the slope or the maximum width of the working area. Point $C$ is the average value of the slope angle of the working side or the width of the working area. The $D$ point is a criterion for limiting the maximum angle or minimum width of the working area. Thus, the main technological indicator for evaluating the mining regime is the operational overburden rate. As a result, proper management of the operational overburden rate will reduce economic costs and get a greater economic effect. 

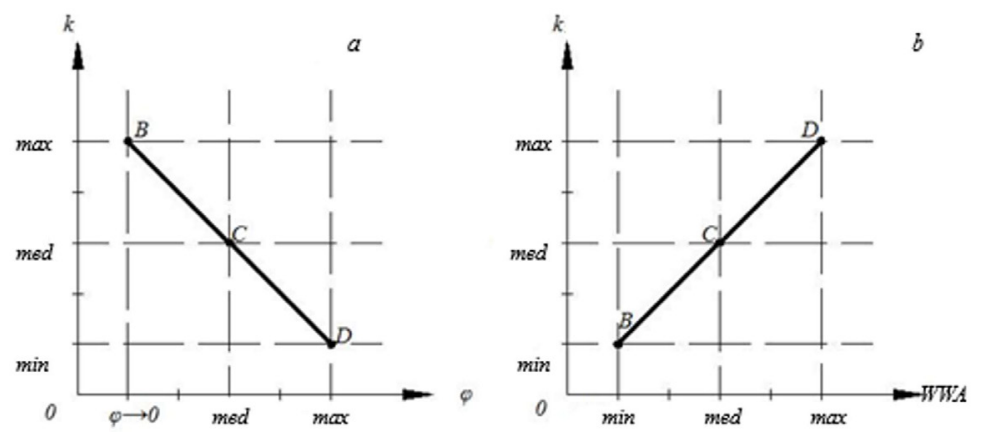

Fig. 4. The dependence of the operational overburden rate on: the angle of the slope of the working side of the quarry $k=f(\varphi)$; b - the width of the working area $k=f$ (WWA) [8].

The described method for determining the overburden rate during the operation of the quarry is implemented in the following order. Based on the pogorizont plans, taking into account the direction of development of mining operations, graphs of the dependence $V=$ $f(P)$ of the increasing volumes of overburden $V$ on the increasing volumes of mineral resources $P$ with the slope angles of the working side of the quarry varying from the minimum to the maximum values (Figure 5) are drawn up.

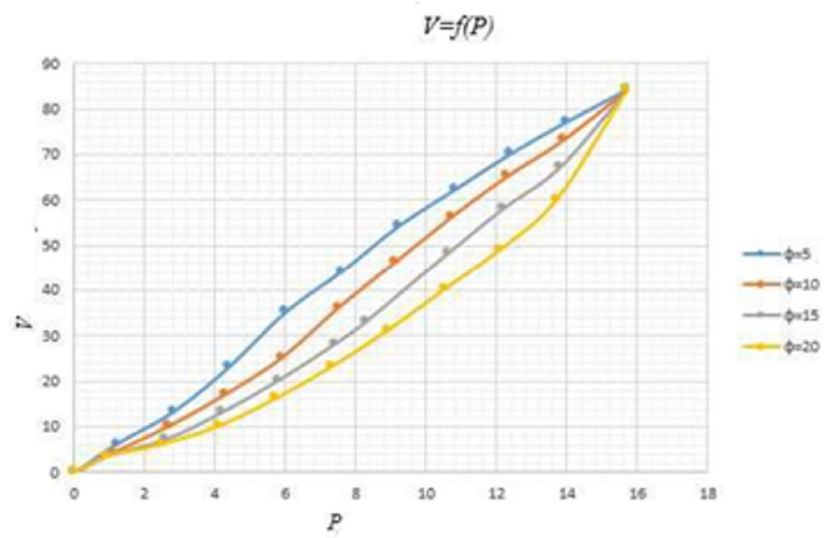

Fig. 5. Cumulative graph $V=f(P)$ of changes in the increasing volumes of overburden $(V$, million $\mathrm{m}^{3}$ ) from the increasing volumes of mineral $\left(P\right.$, million $\left.\mathrm{m}^{3}\right)$, at the angles of the slopes of the working side of the quarry: $\varphi=5^{\circ}, \varphi=10^{\circ}, \varphi=15^{\circ}, \varphi=20^{\circ}[9]$.

A conditional deposit was used to develop the model. The final depth of the quarry is $100 \mathrm{~m}$, the development is carried out by 10 -meter ledges with a slope angle $\alpha=70^{\circ}$, the stable productivity of the quarry for minerals $P=1.57$ million $\mathrm{m}^{3}$. The slope angle of the working side $\varphi$ is taken in the range from $5^{\circ}$ to $20^{\circ}$ with a step of $5^{\circ}$. Possible cases of operation with a constant operational overburden rate can be expressed within the two extreme values of $\varphi_{\min }$ and $\varphi_{\max }$. On the basis of overburden and minerals volumes for each angle of the slope of the working side (Table 1), we obtain an equation that describes each angle of the slope of the working side of the quarry. We define the equations for each angle (from $\varphi_{\min }=5^{\circ}$ to $\varphi_{\max }=20^{\circ}$ ) [9-10].

Table 1. Equations describing the slope angle of the working side of the quarry for different values [10-13].

\begin{tabular}{|c|c|c|c|}
\hline Indicator & $\begin{array}{c}\text { Type of } \\
\text { equation }\end{array}$ & Equation & $\begin{array}{c}\text { Coefficient of } \\
\text { determination }\end{array}$ \\
\hline
\end{tabular}




\begin{tabular}{|c|c|c|c|}
\hline $\begin{array}{c}\text { Angle of slope of the } \\
\text { working side of the quarry } \\
\varphi=5^{\circ}\end{array}$ & Quadratic & $\mathrm{y}=-0.0684603 \mathrm{x}^{2}+6.60752 \mathrm{x}-1.68954$ & 0.99 \\
\hline $\begin{array}{c}\text { Angle of slope of the } \\
\text { working side of the quarry } \\
\varphi=10^{\circ}\end{array}$ & Quadratic & $\mathrm{y}=-0.0624659 \mathrm{x}^{2}+4.54482 \mathrm{x}-1.12557$ & 0.99 \\
\hline $\begin{array}{c}\text { Angle of slope of the } \\
\text { working side of the quarry } \\
\varphi=15^{\circ}\end{array}$ & Quadratic & $\mathrm{y}=-0.183276 \mathrm{x}^{2}+2.50397 \mathrm{x}+0.214529$ & 0.99 \\
\hline $\begin{array}{c}\text { Angle of slope of the } \\
\text { working side of the quarry } \\
\varphi=20^{\circ}\end{array}$ & Quadratic & $\mathrm{y}=0.281534 \mathrm{x}^{2}+0.738268 \mathrm{x}+1.85262$ & 0.99 \\
\hline $\begin{array}{c}\text { Equation of a straight line } \\
(\text { averaging line) }\end{array}$ & Linear & $\mathrm{y}=4.40146 \mathrm{x}$ & 0.99 \\
\hline
\end{tabular}

In this example, the slope angle of the working side is described by a quadratic equation having different $x$ indices. The method is convenient because it is possible to obtain various types of equations. The type of equation determines to some extent the difficulty of solving this problem [13-15].

The straight line that intersects all the curves of the slope angle of the working side of the quarry must be within the two extreme values. The intersection line goes out of the origin (the case when the initial volume of mining operations is not taken into account) and tends to the curve with the maximum slope angle of the working side of the quarry in the final position, because during this period, stable operation of the quarry for overburden rocks and minerals is ensured with the lowest overburden rate [13-15]. Point $B$ is the final value of the averaging line $A B$, when the maximum slope angle of the working side of the quarry is reached, there is no need to average the operational overburden rate. Further development of the quarry will go to the point $C$ at $\varphi=\varphi_{\max }$.

\section{Conclusion}

The main technological indicator for evaluating the mining regime is the operational overburden rate. As a result, proper management of the operational overburden rate will reduce economic costs and get a greater economic effect. The rational mode of mining operations will correspond to the operation of the quarry in the main period according to the average value of the operational overburden rate. In the course of the study, the equations for each angle of the slope of the working side of the quarry were described. According to the accuracy criterion - the rate of determination - the values of the equations for each angle are obtained. This will make it possible to simulate the parameters of open-pit mining operations depending on the specified slope angle and the overburden rate. High values of the determination coefficient confirm that the described mathematical method of averaging the operational stripping coefficient excludes the human factor in calculating the results.

\section{References}

1. V.I. Cheskidov, A.N. Akishev, G.G. Sakantsev, Journal of Mining Science, 54, 10 (2018) 
2. T. Tyuleneva, Proceedings of the 9th China-Russia Symposium "Coal in the 21st Century: Mining, Intelligent Equipment and Environment Protection", 1, 352-356 (2018)

3. V.I. Cheskidov, A.S. Bobyl'sky, A.V. Reznik, Journal of Mining Science, 53, 22 (2017)

4. T.V. Kiseleva, V.G. Mikhailov, G.S. Mikhailov IOP Conf. Series: Earth and Env. Sci. 84012044 (2017)

5. T. Tyuleneva, M. Moldazhanov E3S Web of Conf. 17404061 (2020)

6. R. Sobolevskyi, V. Korobiichuk, V. Levytskyi, Rudarsko Geolosko Naftni Zbornik, 35, 36 (2020)

7. Y. Kudryavtsev, Procedia Engineering: International Conference on Industrial Engineering, ICIE, 2017, 1642-1647 (2017)

8. V. Mikhailov, V. Karasev and G. Mikhailov E3S Web Conf. 4102015 (2018)

9. V.I. Cheskidov, V.K. Norri, Journal of Mining Science, 52, 13 (2016)

10. I.V. Zenkov, B.N. Nefedov, V.V. Zayats, E.V. Kiryushina Eurasian Mining, 41 (2018)

11. T. Tyuleneva, E3S Web Conf. 174, 04019 (2020)

12. C. Carmen, D. A. Talinga, Interpretation, 7, 127 (2019)

13. M. Rezaei, Engineering with Computers, 35, 39 (2019)

14. H. Yang, Z. Liu, D. Zhu, Geofluids, 9856904, 74 (2020)

15. A. Gembalska-Kwiecień Conf. proceedings, 1, 429-436 (2020) 